\title{
Management of Continuous Foreign Language Education in Higher School
}

\author{
Yuliya Timkina ${ }^{1, *}$, Marina Khlybova ${ }^{1}$, Irina Leushina ${ }^{2}$ \\ ${ }^{1}$ Perm State Agro-Technological University named after Academician D.N. Pryanishnikov, Perm, Russia \\ ${ }^{2}$ Nizhniy Novgorod State Technical University named after R.E. Alekseev, Nizhniy Novgorod, Russia
}

\begin{abstract}
Modern higher education in Russia includes three levels of training: bachelor's degree, master's degree and postgraduate courses. Foreign language study is a compulsory part of each level of training. We suppose that the effective formation of foreign language communicative competence is possible when designing a continuous multilevel system of foreign language acquisition in a higher school based on variety. We view a variety in the way that students and teachers are given the freedom to choose an educational variant from a variety of content, technologies, tools and forms based on a selection algorithm. Continuity is achieved by the consistency and succession of the professionally oriented educational content, the nonlinear formation of foreign language sub competencies and the activation of linguistic self-education. The aim of the article is to develop a management system for a continuous foreign language education based on a variety. The management activity is aimed at implementing the educational project in the mass education. The establishment and evaluation of the system includes the determination of strategy and implementation mechanisms, requirements for the programs development and creation of methodological and information supports, mechanisms for quality assurance providing in the professionally oriented foreign language education.
\end{abstract}

\section{Introduction}

Reforming of an education system in the Russian Federation had been reflected in the Education Act (2015) which defined three levels of education: bachelor's degree, master's degree and postgraduate courses. Each level of higher education is aimed at formation of students' competencies required for fitting industry needs. The establishment of competencies is performed on the basis of the federal educational standards of higher education of the Russian Federation, professional standards and also regional industry requirements for the attained level of higher educated graduates. The interaction of the universities with regional enterprises in the field of creation and application of educational programs provides openness of an education system and «acts as the parameter of an order» [1]. The openness of the higher education is designed to establish trust and recognition of quality by involvement of employers as external experts [2], it establishes the ability to change and react to the demands of modern society, to make system transparent and competitive.

The foreign language communicative competence is considered one of the required competencies of the modern specialist in various economic sectors such as industry, agriculture, service. A modern specialist with certain foreign language (mostly English [3]) proficiency is capable of participating in international professional societies, performing professional communication, familiarizing with international experience as well as presenting own professional experience and achievements thereby increasing the overall quality of professional activities.

Successful professional activity in foreign language environment implies the certain level of the respective foreign language communicative competence. The Russian Federation federal standards specify the required level of the foreign language communicative competency. For example, requirements of the standards for foreign language communicative competence for all levels of the "Agro engineering» curriculums include:

1. bachelor's students are to have «the ability to perform oral and written form of business communication in a foreign language» (Russian Federation federal state educational standard, bachelor's degree program 35.03.06 «Agro engineering», 2017);

2. master's students are to demonstrate the ability to employ the contemporary foreign language communicative technologies for academic and professional interaction language (Russian Federation federal state educational standard, master's degree program 35.04.06 «Agro engineering», 2017);

3. postgraduates are to use the contemporary methods and technologies of scientific communication in a foreign language (Russian Federation federal state educational standard for postgraduate students, 35.06 .04 «Technologies and tools of mechanization and power equipment in agriculture, forestry and fish industry», 2015).

The accomplishment of proclaimed requirements for the standards should be based on linguistic personality formation

\footnotetext{
Corresponding author: timkinaj@ mail.ru
} 
[4], on gradual foreign language communicative competence formation in the field of professional activity [5, 6], on ability and readiness to foreign language communication developed on the previous educational stages, on sophistication of speech activity in accordance with cognitive abilities of students [7], on integration of both foreign language communicative competence and professional competencies [8], on providing succession and continuity of educational process [9].

The multilevel foreign language education system in the conditions of a non-linguistic multi-profile university has a number of features. First, significant time gaps in the foreign language training. For example, in some universities, particularly, in the Perm state agro-technological university, undergraduate students study a foreign language during the 1-3 semesters, master's degree students study it during the first semester and postgraduate students have the course of a foreign language during the first two semesters of training. Interruptions in the process of a foreign language study, the lack of a language environment do not contribute to quality results. Secondly, the different incoming level of training of students from beginners to graduates of language schools presumes taking into account the individual characteristics of students, which, as noted in the Exemplary Program for Foreign Language discipline (Exemplary Program for nonlinguistic universities, 2009), should be implemented through two levels of training. The Exemplary Program proposes the implementation of basic and advanced levels of training. In practice, this distribution is not always effective, limits the formation of foreign-language communicative competence to a certain level. Thirdly, the professional orientation of foreign-language education is limited to the views of foreign language teachers about the future professional activity of students, which is subjective as a rule. Those features influence the quality of foreign language training.

It is necessary to determine and introduce new opportunities for the educational process aimed at increasing the overall quality of training. These new combinations are observed in the literature in form of innovations or innovative projects [10]. The innovative educational projects are the key steps to attainment of high quality education due to application of the appropriate means.

The Perm state agro-technological university has made an attempt to develop the continuous multilevel foreign language educational system based on variative approach. The cornerstone of the variety is the developing sensible education, the «extension of variety of the individual's journeys through life» [11]. The variative foreign language educational system based on the theoretical background of variative educational psychology developed by A. Asmolov is focused on development of linguistic personality of a student by departing from unification of educational contents, methods and means towards diversity. Variative foreignlanguage education can be seen as a means of providing students with an opportunity to choose the personally meaningful educational variant based on students' educational needs and cognitive styles. The educational variety gives students freedom to choose the individual educational learning path. Aided by teacher, the students make a choice which fits their personal and professional interests $[12,13]$. The choice algorithm is parameterized by the individual cognitive abilities and particularities, language and self-development skills and abilities.

The continuity of the three-level system within the framework of variative foreign language education is achieved by succession of educational contents towards sophistication of professional tasks [9], nonlinear formation of sub competencies of the foreign language communicative competence, activation of linguistic self-education in the field of upcoming professional activity by using the extracurricular scientific activity. The implementation of the mentioned educational system within the higher educational institution presumes availability of the organizational methodical management.

The paper is aimed at the development of the management system for continuous foreign language education based on the variety which embraces determination of the strategy and implementation mechanisms, development of methodological support and educational programs, information support, educational quality assurance mechanisms.

Introduction of new elements into the educational process assumes not only the existence of approved theoretical and practical foundations but also the developed programme of action. The specific problem setup, assessment of current state, choice of optimal means, efficiency estimates, process analysis and correction based on the monitoring of crucial indicators are the key steps to the attainment of quality foreign language education in a higher school.

\section{Materials and Methods}

In accordance with the educational systems management theory [14], the management system encompasses the following organizational aspects: educational institution viewed as the management object and educational network or complex which implements the educational process. It is worth noting that it does not include the methodology of teaching system and teaching-student interaction which constitutes the subject of pedagogy $[14$, p.26]. The management is aimed at ensuring the adoption of a new educational system, as well as creating proper conditions for its functioning and evolution.

A complex assessment of current state of the management system is conducted upon planning phase of the management activity. This assessment allows one to determine the required changes to apply and availability of resources, and to develop a programme of required management activities. The analysis of the legal normative documents, of the structure and activity of higher school as a management object yields the following results:

- The higher school possesses sufficient amount of freedom in the choice of education content fulfilling the regional demands. The content comprises compulsory and variative institution-specific courses and subjects.

- Higher school structural subdivisions (institutes, departments) have the rights to grant students the individualized curriculum.

- The departments are responsible for the respective educational curricula. The organization of classroom work and students' self-study is performed by the department in accordance with developed and approved plans. 
- $\quad$ The choice of educational technologies and training tools is a responsibility of teachers.

As a consequence, the modern higher school presents favorable environment for implementation of innovative educational initiatives. A flexible higher educational system allows adoption of a project aimed at the selection of content, effective technologies and modern educational tools application.

Development and introduction of continuous variety based foreign language education - do not require substantial changes in the higher educational system as well as additional funding. The project management should be aimed at determining the overall strategy of achieving the project goals, solution methods for specific tasks, curriculum educational resources and methodology recommendations development, information support, as well as internal and external educational quality assurance. These statements will be discussed in greater detail below.

\section{Policy and procedures}

The continuity of education is achieved by the extended and progressive development of the students' foreign language communicative competence. The directional motion is possible when the goal is clearly seen and is of personal significance, the full map of professional activity in the foreign language environment is observable, intermediate results are of practical value, there exist the strict guidelines for problem solutions which suite the personal and professional needs, foreign language skills and cognitive peculiarities of students. In this case the variety implements the student-centralized education.

The succession of the levels of higher education should be fulfilled by the unified component set for foreign language communicative competence. Currently there exists a certain inconsistency and incoherence in determining the goals on each education level. For instance, the bachelor curriculum states the need for the formation of linguistic, verbal, sociocultural and compensatory sub competencies (Exemplary Program for non-linguistic universities for bachelor's degree students, 2009). The components of the master's degree curriculum are the linguistic, socio-cultural, linguo-cultural, social, discursive and compensatory sub competencies (Exemplary Program for non-linguistic universities for master degree students, 2014). Therefore the determining of the unified component contents of the foreign language communicative competence is required which will make it possible to monitor the progress of the sub competencies during the entire educational period.

According to performed functions as stated in the professional standards, the analysis of the component contents makes it possible to determine the key sub competencies crucial for performing professional communication for the bachelor, master and post-graduate students. We consider the unified competence set suitable for professional needs is to be comprised of: linguistic competence (possession of lexical and grammatical units), discursive competence (ability to employ various communication tactics), cross-cultural competence (readiness to perform the cross-cultural communication), strategic competence (ability to compensate the lack of knowledge), pragmatic competence (ability to comprehend and produce statements according to a communicative situation). The aforementioned set reflects all aspects of communication: the communicative, interactive and perceptual, and sufficient level of formation of the components will provide the specialists with foreign language skills and abilities suitable for professional activity.

The variety which permeates all components of the education process, allows one to determine the priority of certain components on different design stages of sub competencies. It makes it possible to design the formation sequence of the sub competencies in accordance with the principle of nonlinearity of the system by targeting the development of educational process on mastering the different aspects of communication. The nonlinearity in the formation of sub competencies is implemented in the classroom work and self-study by compensating the time periods of absence of foreign language courses with general courses implemented with certain elements of foreign language activity. The design of the optimal variant of component formation is considered a part of the continuous educational process.

Procedures for the policy implementation include: developing sub competency based curricula, the occupational program content, design student support for self-directed foreign language acquisition, evaluate measurement and develop criteria for quality assurance. The importance of the teacher should also be noted, whose functions become the revealing and diagnostics of the students' cognitive needs, the monitoring of the sub competencies formation, the management of students' educational and self-educational activities by the joint efforts of teacher and student in order to select optimal educational variant, feedback-based path correction. The proper execution of these functions requires the teacher's mastering in methodical resources, diagnosis methods, up to date educational technologies, basics of the educational management, involvement in research activities. It causes the demands for creation of conditions for selfeducation of teachers, realization of their creative potential, collaboration, exchanges of experience, self and mutual activity assessment.

\section{Design programmes}

When talking about variative educational programs, we should determine the requirements, outline main directions in the students' achievement assessment. The basic requirements will be determined taking into account the principles of openness, professionally-oriented contents to comply with professional standards, the existence of multiple parameter facets (educational contents and technologies, foreign language proficiency levels, practical results).

- The course is designed within the framework of an integrated map in a multilevel system of the foreign language education. Occupying a certain place, the course is built on the basis of the previous course and as a basis for the subsequent ones, which involves the correlation of the practical tasks of the course with the overall objectives of training. The detailed elaboration of the developed sub competencies and the choice of the realization of the sequence are implemented in the modularity of the course. 
The course modules are independent parts, represented by a series of options, filled with meaningful content and development technologies. That is aimed at the possibility of their parallel, inconsistent development and with the possibility of going beyond the limits of the module.

- Variant is the object of choice from a number of elements, united by a single common core, which possesses distinctive characteristics that provides a variety of educational situations. Distinctive characteristics can be meaningful aspects, technologies of accusation, the form of an achieved result etc. The development of options comes from identifying the core obligatory for the development, to fill the distinctive features that are designed based on the needs of students. The requirements for the option include: logical completeness, the receipt of the educational product, implementation instructions, availability of assessment criteria. Significant for our study is the provision of the possibility to carry out diagnostics of the development of sub competencies in the process of solving quasi-professional problems. Thus, the variant should include a certain number of similar quasi-professional tasks, in which a certain foreign language sub competences are actualized.

- Assessment of students acquires greater importance in the form of fixing the achievements of students at a certain level of training. On the one hand, in order for the evaluation to be informative, it is necessary to introduce uniform criteria for the evaluation of the result, including the volume and complexity of the work, the quality of the result. It seems necessary to record the results of mastering each option, which is possible when working with a language portfolio or other services, such as "Pathbrite". On the other hand, the assessment is a feedback for students. Therefore, each task is supplied with the assessment criteria. In this case, the student can visually identify his strengths and weaknesses and potential areas for improvement.

\section{Learning resources and student support}

Since a large proportion of linguistic education takes place in the students' self-study, teaching materials perform not only an information function, but also motivational, organizational, managerial, activity-oriented, controlling functions. Electronic textbooks implement these functions through a variety of graphic tools, hyperlinks to reliable internet resources, interactive exercises, and feedback. Methodical recommendations are intended to assist students in mastering educational variants. We believe that it is extremely important to acquaint students with the goals and objectives of foreign language education, the essence of foreign communicative competence and the characteristics of sub competencies. Only the students' conscious work on the formation of sub competencies can yield the quality results. Therefore, the methodological recommendations introduce students to theoretical positions and give advice on practical work, namely, clear and accessible instructions for the performance of various tasks: the search for foreign sources, the use of metacognitive and compensatory strategies for mastering a foreign language, strategies in various types of speech activity (speaking, writing, listening, reading).

\section{Information systems}

A professionally oriented approach to foreign language teaching assumes the mastery of the future professional activity in a foreign language environment, which explains close cooperation between teachers of the department of foreign languages and graduating departments. It is worth noting that at the postgraduate level with specialized training the role of graduating departments in determining the content of foreign language education prevails. The interaction of all participants in the educational process should be built on the basis of mutual understanding, trust and cooperation, which is possible with full awareness, consent and understanding of ongoing processes. Thus, an open and understandable information system between the participants will provide the conditions for the implementation of the project.

\section{Internal and external quality assurance}

The quality of education within the proposed project should meet the requirements of standards, the requests of regional industry, as well as the personal needs of students. Quality assurance is carried out at two levels:

- $\quad$ internal (the level of the university: the department of foreign languages, graduating departments) - quantitative and qualitative assessment;

- external (the level of other universities and employers) - a qualitative assessment of the expert community.

The purpose of the quality assessment is to attain high levels of training and to provide public feedback in the form of tips for improving or adjusting the educational system [2]. Involvement in the process of evaluating potential employers makes it possible to make a responsible form of the project, more practically focused [15].

\section{Results and Discussion}

The developed system of management of continuous foreign language education in a non-linguistic higher institution on the basis of variety is aimed at improving the quality of language training for graduates of all levels (bachelor's degree, master' degree, postgraduate) and ensuring the effectiveness of the educational system.

Continuity is achieved by designing a nonlinear process of forming sub competencies of foreign language communicative competence during the entire period of training, the continuity of the varying educational paths of students, and the construction of an integral system of foreign language education. The formation of the language personality is realized in conditions of the freedom of choice of personally and professionally meaningful content, technologies and training tools, cognitive features, which fully provides variety in the sense of ability to choose from several options. Involvement of students in self-study is focused on activity, as well as the formation of the competence of lifelong learning.

The management of the system assumes the maintenance of a specially organized activity for the implementation and evaluation of the project. The proposed components of the management system perform the following functions: 
planning (Policy and Procedures, Design Programs) organization (Learning Resources and Student Support, Information Systems), control of quality and effectiveness of education (Internal and External Quality Assurance). The desire to achieve quality indicators for each key management position will ensure the formation of a new educational project.

The value of introducing of this project is justified by the need not only for the theoretical justification of the methodology, but also for practical recommendations for introducing it into mass education in a higher school, proposing specific steps for organizing student-centered education, and creating conditions for self-linguistic education under the guidance of the teacher throughout whole training period. Knowledge and skills are appropriated in active self-study, and foreign language communicative competence is formed.

\section{Conclusion}

The regulatory base of higher schools creates conditions for the introduction of innovative projects in order to improve the educational system. Currently there is a problem of some inconsistency between the levels of higher education, since often each level is considered as separate and self-sufficient. In addition, there is an inconsistency in the tasks of foreign language education, long time gaps between courses, which does not contribute to the quality of training.

The introduction of a continuous system of foreign language education based on variety makes it possible to solve existing problems. The establishment of this system requires the management of an educational project. The organizational and methodological management of continuing education is understood as an activity aimed at the effective organization of the educational process and the achievement of goals in accordance with educational and professional standards. It influences the main components of the educational process, such as defining an overall strategy for achieving the goals, clarifying the implementation mechanisms, developing programs and scientific and methodological support, establishing information exchange between the participants in the process, and determining approaches to the quality assurance.

Updating the components of the educational process and introducing some innovative aspects, the preservation of well-established technologies and the possibility of their selection in accordance with specific incoming data, the opportunity to teach not equally, but individually, makes it possible for bachelor's degree, master's degree and postgraduate students with an extensive foreign language training to be more efficient.

\section{References}

1 E.K. Gitman, A.N. Danilov, I.D. Stolbova, News of higher educational institutions. Technology of textile industry 2 (368), 321-327, (2017)

2 A. Prisacariu, Procedia - Social and Behavioral Sciences 180, 119-126, (2015)

3 I. Sharapova, Y. Kobenko, Procedia - Social and Behavioral Sciences 206, 24-29, (2015)

4 N.I. Almazova, T.A. Baranova, L.P. Khalyapina, Language and Culture 39, 116-134, (2017)

5 A.V. Tsepilova, L.V. Mikhaleva, Language and Culture 2 (22), 129-135, (2013)

6 K.E. Bezukladnikov, B.A. Kruze, Procedia - Social and Behavioral Sciences 200, 393-397, (2015).

7 I. Abramova, E. Shishmolina, Educational Studies Moscow 3, 132-151, (2017)

8 T.S. Serova, E.G. Krylov, Language and Culture 3, 106115, (2015)

9 M. Khlybova, Azimuth research: Pedagogy and Psychology 1 (18), 222-224, (2017)

10 T. Baumann, K. Mantay, A. Swanger, G. Saganski, S. Stepke, Procedia - Social and Behavioral Sciences 226, 243-251, (2016)

11 A.G. Asmolov, Psychology of the XXI Century and the Birth of the Variative Educational Space of Russia, URL: http://www.zankov.ru/about/theory/article $=157 /$ (date of access: 12.02.18).

12 G.A. Krasnoschekova, Language and Culture 39, 209220, (2017)

13 I. Leushin, I. Leushina, Higher education in Russia 6, 51$56,(2017)$

14 D.A. Novikov, The theory of educational systems management (Public education, Moscow, 2009)

15 S. Cicmil, H. Gaggiotti, International Journal of Project Management 36 (1), 208-218, (2018). 